\title{
Imagens do mundo
}

\section{Rafael Elias Teixeira}

\section{Resumo:}

$\mathrm{O}$ artigo pretende trazer alguns apontamentos iniciais sobre a investigação da relação entre as imagens produzidas por meio de aparátos tecnológicos e a construção da realidade na contemporaneidade. Para tanto, parte-se do conceito de realidade como um produto entre o atual e o virtual, e, a partir da análise de três propostas filosóficas existentes, tenta-se explicar como se dá tal fenômeno e como este marca uma mudança profunda nos processos humanos de cognição e percepção do mundo na sociedade tecnológica.

\section{Palavras Chave:}

imagem; técnica; realidade; sociedade tecnológica; contemporaneidade

\begin{abstract}
:
The article aims to bring some initial notes on the investigation of the relationship between the images produced by technological apparatus and the construction of reality in contemporaneity. Thus, it is the concept of reality as a product between the actual and virtual, and from the analysis of three philosophical existing proposals, attempts to explain how this phenomenon happens and how it marks a profound change in human processes of cognition and perception of the world in technological society.
\end{abstract}

\section{Keywords:}

Image; technique; reality; technological society; contemporaneity

\section{Introdução}

$\mathrm{O}$ advento dos meios técnicos de produção e reprodução de imagens e a sua rápida disseminação, tanto no âmbito social quanto no comunicacional em larga escala, notadamente ao longo do século XX e início do XXI, marcam uma mudança importante na relação dos homens com o mundo ao seu redor. Até então, a escrita era a principal fonte de transmissão de conhecimento, sendo responsável por moldar a maneira de pensar do ser humano; com as imagens, toma corpo uma nova forma de se construir a realidade e novos procedimentos cognitivos e perceptivos se desenvolvem, mudando profundamente as sociedades humanas.

Este artigo é uma tentativa de esboçar os primeiros apontamentos feitos a partir de pesquisa em desenvolvimento pelo autor, iniciada no $1^{\circ}$ semestre de 2008 como requisito para obtenção do título de Mestre, na qual a questão que se coloca é de que maneira a imagem tecnicamente produzida interfere na construção da realidade, partindo-se do pressuposto de que a realidade é uma construção dinâmica intersubjetiva. Além disso, tenta-se uma aproximação de tal fenômeno com vistas a conceituá-lo no âmbito da sociedade tecnológica contemporânea e da condição humana nesse novo contexto.

Para tal empreitada, são necessárias algumas delimitações conceituais, com o objetivo de esclarecer alguns pontos básicos para a discussão proposta, e que virão na sequência. 


\subsection{Do conceito de imagem}

As imagens tratadas nesta pesquisa não são aquelas sinônimas de conceito ou idéia, ou seja, não são as criadas mentalmente pelo processo de imaginação - "capacidade para compor ou decifrar imagens" (FLUSSER, 1998, p. 24). São, na verdade, aquelas produzidas por meio de algum aparato técnico.

As imagens tecnicamente produzidas formam uma categoria que abarca a fotografia (estática), o cinema (em movimento), a televisão (possibilidade de instantaneidade), podendo ser obtida por técnicas convencionais ou digitais. Apesar de se tratar de um campo grande e variado, com inúmeras especificidades, a abordagem é teórica, em busca de uma conceituação viável e minimamente identificável como válida para uma compreensão do momento tecnológico presente; por isso, é tomado como princípio a imagem tecnicamente produzida, indiferentemente por qual processo, pois, nesta pesquisa, o foco está nas consequências do produto final na relação com o humano e não no processo por si.

\subsection{Do conceito de técnica}

A técnica, grosso modo, é o conjunto de procedimentos ligados a um determinado tipo de conhecimento, em geral a um adquirido pelo saber científico. No entanto, no âmbito deste artigo, toma-se o conceito empregado pelo filósofo Martin Heidegger, para quem, além do já exposto, a técnica é a mais plena realização da metafísica (1).

Heidegger diz que a metafísica se caracteriza pela passagem do pensar o ser como «ser do pensamento» para pensá-lo como ente, no que há nele de mais geral, constante e imutável. Tal concepção, baseada na interpretação de um determinado ente em detrimento do ser, funda a era metafísica a partir de Platão, responsável pela «coisificação» do mundo, em que os objetos não são mais vistos «em sì, mas sim como produtos de conceitos, os quais, por sua vez, definem como tudo deve aparecer. A técnica, em seu momento atual de onipresença planetária, é metafísica, por constituir ela mesma um conceito de mundo capaz de obscurecer o ser por meio de sua organização inescapável. Segundo esse filósofo, a técnica não é apenas as máquinas ou os instrumentos; ela é uma época do ser específica do seu desenvolvimento, que o desafia e o submete.

\subsection{Do conceito de realidade}

Baseando-se em conceitos de Henri Bergson sobre o objetivo (ou matéria) e o subjetivo (ou duração), o filósofo Gilles Deleuze propõe que os objetos reais possuem duas faces: uma atual e uma virtual.

[...] um «objeto» pode ser dividido de uma infinidade de maneiras; ora, mesmo antes de tais divisões serem efetuadas, elas são apreendidas pelo pensamento como possíveis, sem que nada mude no aspecto total do objeto. Portanto, elas já são visíveis na imagem do objeto: mesmo que não realizadas (simplesmente possíveis), tais divisões são atualmente percebidas, pelo menos de direito. [...] Bergson quer dizer que o objetivo é o «que não tem virtualidade» - realizado ou não, possível ou real, tudo é atual no objetivo. [...] Em resumo, chamaremos objeto, objetivo, não só o que se divide, mas o que não muda de natureza ao dividir-se. É, portanto, o que se divide por diferenças de grau. (DELEUZE, 1999, p. 30)

$\mathrm{Na}$ verdade, a duração divide-se e não pára de dividir-se: eis por que ela é uma «multiplicidade». Mas ela não se divide sem mudar de natureza; muda de natureza, dividindo-se: eis por que ela é uma multiplicidade não numérica, na qual, a cada estágio da divisão, pode-se falar de 'indivisíveis'. Há «outro» sem que haja «vários»; número somente em potência. Em outros termos, o subjetivo, ou a 
duração, é o virtual. (DELEUZE, 1999, p. 31-2)

A partir do movimento processual entre um plano de linhas de forças operantes nos mínimos eventos - o virtual - e tudo o que perdura o suficiente para ser captado por nossos sentidos - formas, matérias, coisas, ou seja, o atual -, torna-se possível a percepção de uma realidade objetiva; o virtual, espaço da conservação do passado e da imanência, é também o das multiplicidades, das quais o atual, espaço da passagem do presente, "atualiza" uma, dando-lhe caráter de realidade. Ou seja, as coisas como elas se mostram são uma forma de atualização do virtual.

As multiplicidades do virtual não se equiparam à noção de «possibilidades», como se houvesse um fenômeno e, virtualmente, muitas possibilidades para ele. Não se trata de quantidades, mas sim de maneiras, de um complexo de conexões compondondo uma só intensidade.

\section{Sociedade tecnológica e imagem}

A sociedade contemporânea é regida pela tecnologia. Como visto, a técnica é mais do que os simples aparelhos utilizados para otimizar a produção de bens; metafísica, ela se espalha por todos os níveis da vida humana, compondo o campo do possível. Não raro, é apontada como um «a priori», um definidor da condição humana. O homem atual, em vez de se utilizar da tecnologia para se libertar, acaba por se tornar escravo dela, trabalhando cada vez mais e tendo cada vez menos tempo para qualquer tipo de reflexão. A técnica se tranformou na última grande narrativa, talvez a única ainda capaz de servir de alento à crise das metanarrativas da pós-modernidade.

O desenvolvimento tecnólogico propiciou a produção e a popularização de artefatos técnicos para captação e produção de imagens. A fotografia, o cinema e a televisão produziram uma verdadeira virada imagética: antes deles, o principal meio de compartilhar conhecimento se dava por meio da escrita, ou seja, muito do que se conhecida do mundo era advindo de conceitos escritos. No entanto, o século XX viu o prestígio da imagem crescer a cada dia, com sua capacidade de transformar processos em cena, de transportar quem a vê para o local onde acontece o fato. $\mathrm{O}$ mundo agora é o das imagens, produzidas alucinadamente pelos meios de comunicação, pelas mais diversas formas de arte visual e pelos usuários ordinários de tecnologia audiovisual, compelidos a registrar todos os momentos em imagens, na tentativa criar algum sentido para suas existências.

Niklas Luhmann propôs que "aquilo que sabemos sobre nossa sociedade, ou mesmo sobre o mundo no qual vivemos, o sabemos pelos meios de comunicação" (LUHMANN, 2005, p. 15); de fato, pode-se nunca ter ido à China, por exemplo, mas ao pronunciar-se o nome da país, uma profusão de imagens vêm à mente, imagens produzidas e disseminadas das mais variadas formas. Essa concepção da realidade por meio das imagens tecnicamente produzidas é, no mínimo, diferente daquela produzida diretamente pelo estar no mundo heideggeriano. Em uma tentativa de compreensão desse fenômeno tão corriqueiro, porém não reconhecível, devido a sua fugacidade, foram selecionadas três correntes filosóficas contemporâneas, apresentadas na sequência para, a partir delas, tentar-se conceituar um princípio teórico a respeito.

\subsection{A imagem técnica de Flusser}

Segundo Vilém Flusser, a humanidade vivenciou duas revoluções na estrutura cultural: a primeira, aproximadamente em meados do $2^{\circ}$ milênio a.C., foi a invenção da escrita linear, inaugurando a História; e a segunda, na atualidade, a invenção das imagens técnicas, produzidas por aparelhos.

As imagens são mediações entre o homem e o mundo; no entanto, elas também têm a capacidade de se entrepor entre eles, deixando de ser mapas do mundo e passando a ser biombos. O homem, nesse caso, passa a viver em função das imagens, em vez de se servir delas em função do mundo. O próprio mundo passa a ser 
vivenciado como um conjunto de cenas. Nesse caso, o homem passa a viver na idolatria da imagem: incapaz de decifrar os siginificados da idéia representada, passa a adorá-las. $O$ homem pré-histórico era essencialmente idólatra e contra isso se voltou a consciência histórica, dirigida contra as imagens.

As imagens tradicionais (desenhos rupestres feitos em cavernas pelos homens pré-históricos) abstraem duas das quatro dimensões do espaço-tempo de um fenômeno para conservar apenas as dimensões do plano; a escrita mantém apenas a dimensão da conceituação, capaz de codificar textos e decifrá-los. Dessa forma, o que era uma tentativa de libertar o homem da abstração das imagens acabou se tornando uma abstração ainda maior, afastando-o ainda mais do mundo.

Com a complexidade cada vez maior da linguagem textual, a capacidade de decifrar as imagens às quais a escrita se propõe a mediar para o homem se tornou uma tarefa praticamente impossível. A linguagem cada vez mais técnica, em busca da precisão, faz com que os textos sejam inimagináveis, ou seja, não há como transformar os conceitos em imagens novamente, fazendo com que os textos sejam feitos de conceitos vazios.

A História é a explicação progressiva de imagens, desmagicização, conceptualização. Lá, onde os textos já não significam imagens, nada resta a explicar, e a história pára. Em tal mundo, as explicações passam a ser supérfluas: um mundo absurdo, o mundo da actualidade. (FLUSSER, 1998, p. 31)

As imagens técnicas são produzidas por aparelhos tecnológicos. A técnica utilizada é um texto científico aplicado, fazendo com que as imagens técnicas sejam produtos indiretos de textos. Elas aparentemente não precisam ser decifradas, pois seu significado imprime-se automaticamente sobre suas superfícies, fazendo com que sua relação com o mundo seja apenas de causa e efeito.

O mundo representado parece ser a causa das imagens técnicas, e elas próprias parecem ser o último efeito de uma complexa cadeia causal que parte do mundo. O mundo a ser representado reflete raios que vão sendo fixados sobre superfícies sensíveis, graças a processos ópticos, químicos e mecânicos, assim surgindo a imagem. Aparentemente, pois, imagem e mundo encontram-se no mesmo nível do real: são unidos por uma cadeia ininterrupta de causa e efeito, de maneira que a imagem parece não ser um símbolo e não precisar de deciframento. Quem vê a imagem técnica parece ver o seu significado, embora indirectamente. (FLUSSER, 1998, p. 34)

Tal característica faz com que sejam vistas como janelas para o mundo e não imagens, passando uma sensação de confiabilidade. No entanto, são tão simbólicas quanto qualquer imagem, apenas são mais complexas de serem decifradas, pois no caso da imagem tradicional, por exemplo uma pintura, há um agente humano que a produz, colocando-se entre a imagem e seu significado, ou seja, os símbolos são elaborados pelo agente humano, transferidos para o pincel e transpassados para a superfície. Portanto, para a decifração da imagem tradicional, é necessário se conhecer o que se passou com o agente no momento da elaboração. Já na imagem técnica, há um agente humano e um aparelho, os quais, aparentemente, não interferem na impressão do real na superfície, ou seja, o conjunto agente humano-aparelho aparenta ser apenas um canal transmissor e não um codificador no processo.

O homem atual vive na idolatria das imagens, assim como o homem pré-histórico, entretanto agora é no campo da técnica; ele transfere a magia da imagem (a capacidade de transformar processos em cenas) para o mundo. Vivendo magicamente, ele deseja que tudo se torne imagem técnica, alçada à condição de memória eterna de qualquer empenho humano; como ela é o objetivo de todo ato, passa de ser histórica para tornar-se um ritual de magia. Ela incorpora a tudo e a todos, não oferecendo alternativas. Portanto, a característica metafísica da técnica, já apontada por Heidegger, apresenta-se novamente. 


\subsection{A hiper-realidade de Baudrillard}

Jean Baudrillard apresenta a questão da imagem como uma forma de simulação, algo que finge existir algo que não existe. Não há mais diferença entre o real e a simulação; na verdade, a própria simulação ocupa o lugar do real. Segundo ele, a imagem possui quatro sucessivas fases: "[...] ela é o reflexo de uma realidade profunda; ela mascara e deforma uma realidade profunda; ela mascara a ausência de uma realidade profunda; ela não tem relação com qualquer realidade: ela é o seu próprio simulacro puro" (BAUDRILLARD, 1991, p. 13). A passagem das imagens que dissimulam (fingem não existir) algo para as que dissimulam não haver nada é a virada decisiva do universo da representação para a era dos simulacros e da simulação. Em resposta à perda do real, produz-se mais signos do real: o que traz em si algum sinal de realidade, de algo vivido, é valorizado. Essa produção descontrolada de signos de realidade tem como consequência uma condição em que a consciência humana não mais é capaz de distinguir o real da fantasia e o real é construído cada vez mais saturado, real mais que real: é a hiper-realidade.

A lógica da simulação opera com a não-equivalência: assim como a moeda simula ter um valor que não possui em si mesma, a imagem não mais precisa equivaler a um real por trás dela. Esse modelo é bem condizente com a questão da produção digital de imagens: o real é produzido por uma combinação binária infinita, podendo ser criado e recriado de infinitas formas e intensidades.

O real é produzido a partir de células miniaturizadas, de matrizes e de memórias, de modelos de comando - e pode ser reproduzido um número indefinido de vezes a partir daí. Já não tem de ser racional, pois já não se compara com nenhuma instância, ideal ou negativa. É apenas operacional. Na verdade, já não é real, pois já não está envolto em nenhum imaginário. É um hiper-real, produto de síntese irradiando modelos combinatórios num hiper-espaço sem atmosfera. (BAUDRILLARD, 1991, p. 8)

A sociedade tecnológica contemporânea é o espaço para a simulação por excelência. Nela, as imagens, cada vez mais vívidas, coloridas e ricas em detalhes, aparentam ser mais reais do que a própria natureza. As imagens, que a princípio deveriam representar o mundo, acabam por se transformar em um parâmetro para ele. A técnica ocupa o lugar do homem e passa a ser ela a medida de todas as coisas.

\subsection{A caverna orbital de Kamper}

Para Dietmar Kamper, as imagens possuem a função ancestral de ocupar o lugar do vazio. Elas surgiram como uma resposta à dúvida da morte: como não se sabe explicá-la, nem ao menos se sabe como lidar com ela, cria-se uma imagem para representá-la. As imagens, portanto, trazem em si a imortalidade.

Entretanto, com a profusão de imagens na contemporaneidade, ocorre o seguinte fenômeno: como tudo é representado por imagens, inclusive o próprio homem, diferentes temporalidades convivem simultaneamente; a partir disso, surge uma sensação de indeterminação de se estar vivo ou morto.

Os homens hoje vivem no mundo. Não vivem nem na linguagem. Vivem na verdade nas imagens do mundo, de si próprios e dos outros homens que foram feitos para eles. E vivem mais mal do que bem nessa imanência (permanência) imaginária. Morrem por isso. No ápice da produção de imagens existem maciços distúrbios. Existem distúrbios das imagens que tornam enormemente ambígua a vida das imagens e a morte pelas imagens. Se difunde uma condição do tipo "morto-vivo", "vida morta". Essa impossibilidade de decidir se se está ainda vivo ou morto adere às imagens, pelo menos no momento da sua pura simulação sem referência. (KAMPER, 2002, p. 7)

A produção e a distribuição em escala de imagens também colaboram para a perda de sentido na 
contemporaneidade. Quanto maior a sua quantidade, menor a memória e menor a capacidade das pessoas de recontarem suas próprias biografias, colaborando para a fragmentação pós-moderna.

Com as imagens não é possível nem recordar nem esquecer. Sobre esse limite se trabalha continuamente. Em outras palavras, o imaginário é aquele querer esquecer que recorda e aquele querer recordar que esquece. E precisamente quanto menos imagens (a favor de uma única imagem) melhor a lembrança [...]. (KAMPER, 2002, p. 11)

Nesse contexto, a humanidade se vê presa em uma verdadeira caverna orbital, composta de imagens circundantes por todos os lados. Nela, é praticamente impossível o surgimento do novo, pois as imagens apenas repetem o já visto e o já vivido, são como espelhos refletindo sempre o mesmo reflexo. As vivências são sempre de segunda mão, não há experiências novas, tudo é sempre uma releitura. As imagens, pois, aprisionam os homens em seu fascínio e em sua transparência turva.

\section{Esboços de uma teorização sobre a imagem}

A vivência humana muito tem se alterado com a hegemonia da técnica, capaz de moldar o mundo ao seu modo. No campo da técnica, as imagens cumprem o papel de propagadora do ideário tecnológico, espalhando-o para os mais diversos extratos sociais pelo planeta.

A imagem tecnicamente produzida é, atualmente, o principal meio de interação que se tem com o mundo; em sua onipresença, dá ao homem as medidas de todas as coisas, entronando a técnica no lugar que um dia já fora dele na história do conhecimento. Dessa forma, acabam por alterar profundamente o processo de construção da realidade.

$\mathrm{Na}$ concepção deleuziana do objeto real, apresentada anteriormente, o virtual ocupa um lugar de grande importância: é nele em que a multiplicidade acontece, a partir dele algo se atualiza; é, portanto, o ambiente propício para a variação, o novo. O virtual também está relacionado ao plano da imanência, território-base de onde surgem os conceitos, ou seja, é pré-conceitual, pré-filosófico. O plano de imanência é o que vem antes de tudo, é o plano do acontecer, o que dá pulsação viva a cada fato.

Uma mudança que se pode notar na construção da realidade a partir das imagens tecnicamente produzidas é que estas, por serem derivadas de textos e, aparentemente, não serem decifráveis (inimagináveis), não possuem o componente vivo, pré-conceitual, imanente. Ou seja, por já serem «conceituais», não abrem espaço para a multiplicidade, são fechadas em si mesmas, afinal, seu significado, aparentemente, como bem lembra Flusser (2), já está em sua superfície, não cabendo aí nenhuma decifração.

Nesse contexto, o novo dificilmente surgirá. A realidade das imagens é pobre em vivacidade, por mais saturada de signos do real que esteja; não abre espaço para o diferente, para o acontecimento transformador; dificilmente, na relação direta entre a consciência e a imagem, o sentido (3) aparecerá.

Por outro lado, a grande quantidade de imagens, característica da sociedade tecnológica, propicia a fragmentação da memória e seu enfraquecimento. Sem memória, as pessoas tornam-se incapazes de recontar suas próprias histórias, não firmando a identidade do eu (4) .

A necessidade crescente das pessoas de registrarem com imagens todos os momentos provavelmente esteja relacionado com a perda da capacidade da narrativa auto-biográfica. Sem memória e sem uma história para contar, resta a elas apenas ilustrar sua vida para os outros, tentando dessa forma uma imortalidade pela imagem. Tal fato também serve como mais um potenciador para a técnica: cada vez mais tornam-se escravos da técnica, da necessidade de produzir imagens, de perder momentos da vida para se dedicar a um aparato 
técnico.

Há um sentimento generalizado de nostalgia do mundo, uma falta de vivências e experiências perdidas. Às pessoas, alijadas da memória, da auto-biografia e entorpecidas pela tecnologia, resta buscar um sentido para suas existências em produtos culturais que lhe tragam algum vestígio de realidade; em função disso, a grande popularidade de produtos culturais com «selo» de realidade: na televisão, «reality shows»; no jornalismo, a busca incessante pela instantaneidade do fato; no mercado editorial, as biografias e auto-biografias publicadas em maior quantidade a cada ano; no cinema, o fortalecimento do documentário e do hiper-realismo; e na internet, os ambientes de realidade virtual. As pessoas, sem poder identificar o que lhes falta, embarcam nessas aventuras, na tentativa de suprir o vazio de suas vidas.

\section{Possíveis fugas}

É impossível negar o papel da técnica na atualidade. Ela é responsável por mediar a maior parte de nossas ações. No entanto, é importante se ter um conhecimento de quais são seus efeitos na vida humana para poder, de alguma maneira, conviver de forma saudável com ela. Assim como as imagens: é impossível se pensar a vida cotidiana sem aliá-la a imagens produzidas.

Uma possibilidade para melhorar nossa relação com as imagens tecnicamente produzidas é o próprio estudo sobre elas. A partir da discussão de seus componentes, de suas implicações filosóficas e consequências psicológicas e sociais, é possível ter consciência de todo o processo e usá-lo da melhor forma; o que não é aceitável é encarar a tecnologia como inatacável, indiscutível e infalível. Um sujeito bem formado e informado é capaz de lidar com todas essas questões com muita mais leveza e de usar a técnica a seu favor.

A arte sempre teve e continua tendo uma papel transformador da consciência humana, e por isso pode ser utilizada como um meio de superar as amarras produzidas pelas imagens. Novas experimentações audiovisuais, em que se pense a relação da imagem e a consciência dos indivíduos, e que subvertam a lógica imagética pré-concebida, auxiliando na sua decifração e propiciando novos sentidos, podem auxiliar no conhecimento dessa área.

O contato interpessoal também é capaz de modificar essa situação. A imagem é sempre uma relação de sujeito-objeto, ou seja, o indivíduo passa a se relacionar com o mundo e com as pessoas como quem se relaciona com coisas. A comunicação pessoa a pessoa, com a valorização da alteridade e o respeito ao outro como indivíduo único, é uma saída para a visão utilitarista das relações humanas.

Uma volta ao mundo, ao «estar no mundo», também é bem-vinda nessa busca por saídas da relação desigual com a técnica e com as imagens. Deve-se buscar vivenciar novamente o mundo, buscar outras sensibilidades, utilizar os outros sentidos, não apenas o visual. Essa ressensibilização pode ser um antídoto ao cansaço visual generalizado e ao sentimento de enfado tão presente na contemporaneidade.

\section{Bibliografia:}

BAUDRILLARD, Jean. Simulacros e simulação. Lisboa, Relógio d'Água, 1991.

BRUNER, Jerome. "Life as narrative". Social research, v. 71, n. 3, fall 2004, p. 691-710.

DELEUZE, Gilles. Bergsonismo. São Paulo, Editora 34, 1999. 
Lógica do sentido, 4. ed. São Paulo, Perspectiva, 2007.

FLUSSER, Vilém. Ensaio sobre a fotografia: para uma filosofia da técnica. Lisboa, Relógio d'Água, 1998.

HEIDEGGER, Martin. Introdução à metafísica, 4. ed. Rio de Janeiro, Tempo Brasileiro, 1999.

.Question concerning technology and other essays. New York, Harper USA, 1977.

. Ser e tempo. Petrópolis/Bragança Paulista, Vozes/Universitária São Francisco, 2006.

KAMPER, Dietmar. "Imagem". In: WULF, Christoph. Cosmo, corpo, cultura: enciclopedia antropologica. Milão, Mondadori, 2002. Disponível para download em: http://geccom.incubadora.fapesp.br/portal/referencias/textos/kamper/imagemkamper.pdf/view

LUHMANN, Niklas. A realidade dos meios de comunicação. São Paulo, Paulus, 2005.

MARCONDES FILHO, Ciro. O escavador de silêncios: formas de construir e desconstruir sentidos na comunicação. São Paulo, Paulus, 2004.

\section{Notas}

(1) Para um aprofundamento, conferir: HEIDEGGER, 1999.

(2) Conferir subtítulo 2.1 "A imagem técnica de Flusser".

(3) “O sentido é a quarta dimensão da proposição. Os Estóicos a descobriram com o acontecimento: o sentido é o expresso da proposição, este incorporal na superfície das coisas, entidade complexa irredutível, acontecimento puro que insiste ou subsiste na proposição.” (DELEUZE, 2007, p. 20)

(4) A esse respeito, conferir: BRUNER, 2004.

\section{Mini Currículo}

Graduado em Comunicação Social com habilitação em Editoração pela Escola de Comunicações e Artes da Universidade de São Paulo (ECA/USP) e mestrando em Ciências da Comunicação pela ECA/USP. Contato: rafaelelias@gmail.com. 